\title{
On One Method of Correlation and Spectrum Estimation Development
}

\section{V.P. Denisiuk, O.V. Denisiuk}

National Aviation University, Ukraine.E-mail: kvomden@nau.edu.ua

Received 1502 2005, accepted 06032006

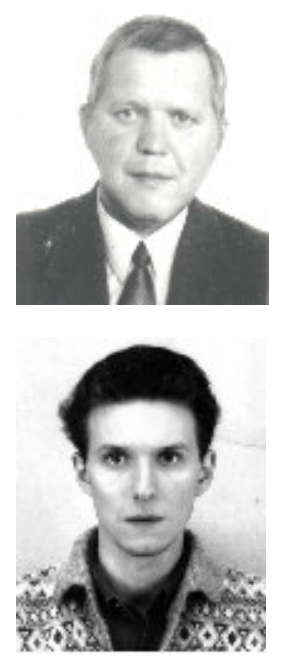

\author{
Volodymyr DENISIUK \\ Date and place of birth: 1945 in Kiev, Ukraine.
}

Education: 1973 - Mechanical-mathematic faculty of the Kiev State University named after T. Shevchenko. Affiliations and functions: 1996, Dr. Sc. (Physics and Math.).

Research interests: theory and methods of spline functions in the problems of signal processing and in the tasks of mathematic-physics.

Teaching: Mathematics.

Publications: Author of more than 70 scientific articles; co-author of 1 monograph and 3 textbooks.

Present position: Head of the Department of Higher and numerical mathematics of the National Aviation University. Tel. (044) 497-70-26.

\author{
Oleg DENISIUK \\ Date and place of birth: 1975 in Kiev, Ukraine, \\ Education: 1998; Instrument Design Faculty of the National Technical \\ University, Ukraine "Kiev Polytechnic Institute" \\ Research interests: Methods of spline functions in the problems of signal processing. \\ Publications: Author of more than 7 scientific articles. \\ Present position: engineer.
}

\begin{abstract}
The article deals with a non-linear method of correlation function and spectrum power density estimation for which analogies of A. Shuster's periodic diagrams have been used. The effect of frequency expansion particularly compensates wellknown aliasing frequency effect. It was shown that if different properties of a random process are taking into account, it will allow to get the estimation of spectrum power density, the order of decrease of which corresponds to these differential properties.
\end{abstract}

Keywords: spline; periodic diagram; correlation function; spectrum power density; order of decrease.

\section{Introduction}

During realization of numerous scientific and technological problems, it is often necessary to evaluate the correlation function and the power spectrum density of stationary random processes, which can be regarded as models of signals under research. Two approaches can exist for this case. If one of these approaches is applied (which is considered to be a direct one) the correlation function is estimated first of all, and then with its help on he basis of Fourier transformations the power spectrum density of can be regarded.

In case of the second approach, which is non-direct, the power spectrum density is estimated at first, and then on the basis of Fourier transformation the correlation function is determined. Both approaches lead to almost the same results [1].

When practically applied, continuous signals after discretization performed are changed by means of the values succession; then statistic characteristics of this succession are regarded as statistic characteristics of continuous signals.

However, there exist some properties of these signals, which can be completely lost during the discretization process; different properties of signals can be mentioned among them. As it is know the very properties of these signals determine both the character of the decrease of power spectrum density of signals and differential characteristics of the correlation function $[4$, $6,3]$.

Taking into account the mentioned above, it is possible to formulate the problem, to obtained the estimation of power spectrum density and the correlation function, the properties of which are coordinated apriority with known differential features of signals under investigation. One method of this problem solution is the subject of this paper. 


\section{Object and methods}

Let us assume that the realization $\xi(t)$ of stationary (in general) argotic to the fourth moment random process $X(t)$ is observed on the segment $[0, T]$. This process is assumed as differential by $k(k=1,2, \ldots)$ times.

As a result of discretization, the realization $\xi(t)$ of this process is replaced by the sequence of $\left\{\xi_{i}\right\}_{i=1}^{N}$ its node values of $\xi\left(t_{i}\right)=\xi_{i}$ for equally distributed moments of time $t_{i}, t_{i}=i * h$. Here $h$ is the step of discretization.

For the evaluation of the correlation functions and power spectrum density, the properties of which are coordinated with differential characteristics of the process under research, the non-direct method can be applied, at which firstly we estimate the power spectrum density and then the estimation is provided for the correlation function.

As it is known, in the function of the estimations of power spectrum density at the frequency $\omega$ periodic diagrams are used which can be determined in the following way [1]:

$$
g(\omega)=\left.\left.\frac{1}{T}\right|_{0} ^{T} \xi(t) e^{i \omega t} d t\right|^{2}
$$

Because Furrier transformations in the finite limits are completely determined by the values of the discrete frequencies $\omega_{j}=\frac{2 \pi}{T} j,(j=1,2 \ldots ., N)$ we can instead of (1) analyze the estimation [7]:

$$
g\left(\omega_{j}\right)=\frac{1}{T}\left|\int_{0}^{T} \xi(t) e^{i \frac{2 \pi}{T} j t} d t\right|^{2}
$$

Taking into account that when we estimate power spectrum density and the correlation function, frequency phases can be neglected, and realization can be continued by means of even approach on the segment $(-T, 0)$; at this only and (2) can be written as

$$
g\left(\omega_{j}\right)=\frac{2}{T}\left(\int_{0}^{T} \xi(t) \cos \frac{2 \pi}{T} j t d t\right)^{2}
$$

In order to calculate the estimations according to formula (3), we can use Felon's method; for the coordination the rate of decrease of the spectrum estimations with the differential properties of the process under investigation, we can replace the realization $\xi(t)$ by the even trigonometric spline $\operatorname{St}(\xi, r, N, t)$, which has the continues derivative of $\mathrm{r}$ and satisfies conditions of $\operatorname{St}\left(\xi, r, N, t_{j}\right)=\xi_{j}, j=1,2, \ldots, N$.

Such spline can be writhen as follows:

$$
\operatorname{St}\left(\xi, r, N, t_{j}\right)=\sum_{j=1}^{N} \xi_{j} s t_{j}(r, N, t)
$$

where $s t_{j}(n, N, t) \quad-$ fundamental trigonometric splineswhich have been analyzed in (6).

If we substitute (4) in (3) and make not complicated transformation, we can obtain

$$
g\left(\omega_{j}\right)=\left[\frac{a_{j}^{*}}{j^{r+1} \Psi_{j}(r, N)}\right]^{2},
$$

where $a_{j}^{*},(j=1,2, \ldots)$ are values which can be calculated on the basis of the following formula:

$$
\begin{aligned}
& a_{j}^{*}=\frac{2}{N} \sum_{k=1}^{N} \xi_{k} \cos \frac{\pi k}{N} j \\
& \Psi_{j}(r, N)=-(-j)^{-(r+2)}+ \\
& +(2 \pi N)^{-(r+2)}\left[\zeta\left(r+2, j N^{-1}\right)+\zeta\left(r+2,-j N^{-1}\right)\right],
\end{aligned}
$$

where $\xi(\mathrm{k}, \mathrm{n})$ - Ramón's function.

It is necessary to note that using formula (6) we can calculate only $N$ of different coefficients $a_{j}^{*}$; at $j>N$ coefficients $a_{j}^{*}$ create periodic succession, which is not decreased in general. But, because of additional multipliers in (5) we can calculate any numerical values estimation $\mathrm{g}\left(\omega_{j}\right)$, the order of decrease coordinates with known properties of signals.

Because we have obtained the numerical multipliers of power spectrum density estimations we can propose a very interesting conclusion: i. e.: during integrals calculations which are included in to estimations (3) obtained by Felon's method, the effect of "frequency expansion" is observed. This effect stays opposite to the known effect of the frequency aliasing that takes place as a result uniform time discritization [8].

It is evident, that the frequency expansion process is determined by the chosen method of interpolation. In particular, only in case when differential properties of interpolating function and realization are concerted the frequency expansion corresponds well to properties of investigated process.

To provide this coordination of differential properties in a general case becomes possible only when the interpolation of the realization is carried out by splines.

So, we have hare obtained estimations of power spectrum density, the order of decrease of which has been matched, which differential properties of the process under research.

Determining the dispersion of the power spectrum density estimations by the proper method, we can get

$$
\sigma^{2}\left(\omega_{j}\right)=g^{2}\left(\omega_{j}\right)=\left[\frac{a_{j}^{*}}{j^{r+1} \Psi_{j}(r, N)}\right]^{4}
$$

Dispersions of (5) of power spectrum density in case we have the multiplier $\left[j^{r+1} \Psi_{j}(r, N)\right]^{-1}$ are less in comparison with the dispersion estimations which hare been obtained by the method of periodic diagrams. This phenomenon can be explained by the effect of "frequency expansion" which to a certain extent compensates the effect of "frequency superposition". 
In order to achieve the further decrease of dispersion, it is possible to use methods of smoothing, which are found in article [5].

We can write the formula

$$
R(\tau)=\sum_{j=1}^{N} g\left(\omega_{j}\right) \cos \omega_{j} \tau
$$

Based on the properties of Furrier transformations, we can say that the estimation of the correlative function that is demonstrated by expression (6) is the function, which has the continuous derivative of 2 orders. It is well correlated with $[4,6]$.

\section{Conclusions}

The method of estimation of development of spectrum power density and correlation function of random process with given differential properties has been described in this article. The implemented (succession) expansion of random process values which has been obtained after discretization is interpolated by splines, whose differential properties are well concerted with those of the investigated processes. Then Fourier transformations are calculated by Filon's method. The obtained estimation method for the spectrum power density can be applied for correlation function determination.

The proposed approach of estimations of spectrum density power allows to achieve a concordance between the order of these estimations decreasing and the known differential properties random process. Besides, this concordance significantly reduces the distorting influence of the frequency aliasing effect, which is one of results of the primary discretization.

The proposed method can be applied in various fields of scientific researches.

\section{References}

1. Бендат Дж., Пирсол А. Измерение и анализ случайных процессов. - М: Мир, 1974. - 464 с.

2. Денисюк В.П., Денисюк О.В., Марченко Б.Г. Моделювання вимірювальних сигналів класами фундаментальних функцій // Актуальні проблеми автоматизації та інформаційних технологій. Дніпропетровськ: Навчальна книга, 2000. - Т. 1. С. 31-38.

3. Колмогоров А.Н., Фомин С.В. Элементы теории функций и функционального анализа. - М.: Наука, 1968. - 496 с.

4. Леви П. Стохастические процессы и броуновское движение. - М.: Наука, 1972. - 376 с.

5. Марпл С.Л. Цифровой спектральный анализ и его приложения. - М.: Мир, 1990. - 584 с.

6. Свешников А.А. Прикладные методы теории случайных функций. - М.: Наука, 1968.

7. Снеддон И. Преобразование Фурье. - Л., 1955. $667 \mathrm{c}$.

8. Хемминг Р. Численные методы. - М.: Наука, 972. $-400 \mathrm{c}$. 